\title{
STUDY OF EROSIVE WEAR BEHAVIOUR ON SIC/SIC COMPOSITES
}

\author{
MIN-SOO SUH* \\ School of Advanced Materials Engineering, Kookmin University, 861-1 \\ Jeongneung-dong, Seongbuk-gu, Seoul 136-702, Republic of Korea
}

\begin{abstract}
In the field of aerospace propulsion system, erosive wear on continuous silicon carbide ( $\mathrm{SiC}$ ) fibre-reinforced $\mathrm{SiC}(\mathrm{SiC} / \mathrm{SiC})$ composites is of significant issue to achieve high energy efficiency. This paper proposes a crucial factor and a design guideline of $\mathrm{SiC} / \mathrm{SiC}$ composites for higher erosion performance regarding cost effectiveness. Fabrication and evaluation of impacts and wear on $\mathrm{SiC} / \mathrm{SiC}$ composites are successfully carried out. Erosive wear behaviours of the CVI and the LPS composites evidently show that the crucial fabrication factor against solid particle erosion (SPE). Erosive wear mechanisms on various $\mathrm{SiC} / \mathrm{SiC}$ composites are determined based on the analysis of erosive wear behaviour. Designing guideline for the $\mathrm{SiC} / \mathrm{SiC}$ composites for pursuit of high erosion performance is also proposed as focusing on the followings; volume fraction of matrix, strength of the matrix, bonding strength, and PyC interface.
\end{abstract}

Keywords: $\mathrm{SiC} / \mathrm{SiC}$ composite, erosive wear, designing guideline $\mathrm{SiC}$, fibre-reinforced composite.

\section{Introduction}

The inception of technological breakthrough in the historical viewpoint is frequently meditated by the state-of-the-arts in material science and engineering. SiC fibrereinforced $\mathrm{SiC}$ matrix $(\mathrm{SiC} / \mathrm{SiC})$ composite is one of the cutting edges of material science, which perfectly meets the constant demands of superior material in the nuclear energy system and the aerospace propulsion system regarding energy science ${ }^{1-9}$. Wear is one of significantly important phenomena to control for the higher durability and reliability of mechanical components ${ }^{1-7}$. In the field of aerospace propulsion system, erosive wear on $\mathrm{SiC} / \mathrm{SiC}$ composites is of significant issue to achieve high energy efficiency with sustainability $^{3-7}$. In the same purpose, the world's famous jet fighter engine also decided to adopt $\mathrm{SiC}$ matrix composites and now successfully moving to the fourth stage of research.

This paper goes along with the warmest atmosphere based on academic knowledge, and proposes a crucial factor and a design guideline of $\mathrm{SiC} / \mathrm{SiC}$ composites for higher erosion performance regarding cost effectiveness.

\section{${ }^{*}$ Corresponding author.}

E-mail address: mssuh@kookmin.ac.kr, Min.S.Suh@gmail.com (M.-S. Suh). 
A number of $\mathrm{SiC} / \mathrm{SiC}$ composites are prepared by two general fabrication routes viz. chemical vapour infiltration (CVI), and transient eutectic liquid phase sintering (LPS). As shown in Table 1, LPS route also divided into two different fabrication processes regarding to the adaptation of pyrolytic carbon $(\mathrm{PyC})$ interfaces ${ }^{5,6}$. The detail methods of fabrication ${ }^{6,8}$, and test of impact ${ }^{7}$ and wear ${ }^{3-6}$ are described in elsewhere.

Briefly, it is the test of material performance against foreign object debris (FOD) but the diversity of sizes of projectile in the range of $3 \mathrm{~mm}$ to $500 \mu \mathrm{m}$; it is divided into two categories, the ballistic impact and the solid particle erosion (SPE).

Table 1. Fabrication characteristic of various route for $\mathrm{SiC} / \mathrm{SiC}$ composite

\begin{tabular}{lccc}
\hline & CVI & LPS & LPS-P* \\
\hline Route & Reaction gas deposition & SiC powder + sintering additives \\
\hline Process temperature & $1000^{\circ} \mathrm{C} \sim$ & & $1700{ }^{\circ} \mathrm{C} \sim$ \\
\hline Matrix-fibre interface & Chemical vapor deposited PyC & Pre-pyrolyzed PyC \\
\hline Porosity & $\sim 20 \%$ & $\sim$ near zero & $\sim 6 \%$ \\
\hline
\end{tabular}

*LPS-P: Phenolic resin interface fibre-reinforced composite

\section{Erosive Wear on $\mathrm{SiC} / \mathrm{SiC}$ Composites}

\subsection{Particle Impact and Erosion Behaviour}

Composite is sometimes the only and inevitable choice to answer the purpose, due mainly to the brittle nature of ceramics ${ }^{1-10}$ well-known as fracture mechanisms subjected to most of wear contacts, especially under sliding ${ }^{1-2}$ and $\operatorname{erosion}^{3-6}$. In addition, the impact performances of monolithic $\mathrm{SiC}$ ceramics and $\mathrm{SiC} / \mathrm{SiC}$ composites in the range of impact energy of $0.05 \mathrm{~J}$ to $0.0067 \mathrm{~J}$ clearly show not only the limitation of monolithic but also strongly supports the greatest needs of composites for the structural applications ${ }^{7}$ (Fig. 1). $\mathrm{SiC} / \mathrm{SiC}$ composites manufactured by the route of the CVI and the LPS, both commercially available, were evaluated in order to clarify a crucial fabrication factor for

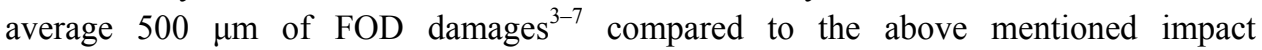
assessment ${ }^{7,9}$.

Erosive wear behaviours of the CVI and the LPS composites depicted in Figure 2 evidently show that the crucial fabrication factor against SPE is that the strength of the matrix rather than the other constituents of composites, namely, fibre bundles and PyC interfaces.

It was the dominant reason of the trial fabrication of $\mathrm{SiC} / \mathrm{SiC}$ composite materials in a novel route -the pursuit of high erosion performance regarding cost effectiveness- by means of altering the conventional coating method and an in situ crystallization of all constituents including the matrix and fibre bundles. 

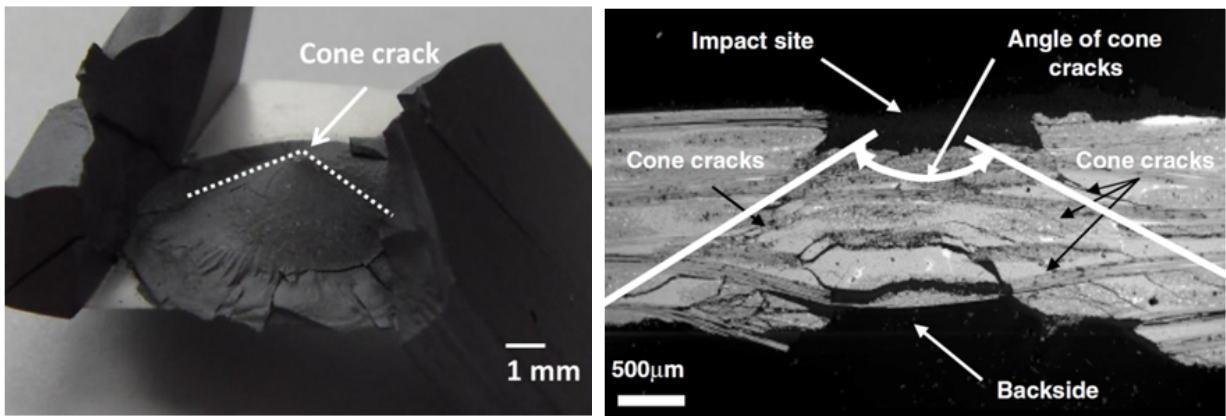

Fig. 1. Fractured CVD-SiC monolithic $(\mathrm{t}=3 \mathrm{~mm})$ within the generation of cone crack by the impact of steel ball at $100 \mathrm{~m} / \mathrm{s}$ velocity compared to the unfractured $\mathrm{SiC} / \mathrm{SiC}$ composite $(\mathrm{t}=2 \mathrm{~mm})$ at $400 \mathrm{~m} / \mathrm{s}$ impact ${ }^{9}$.

Aforementioned fibre bundle is comprised of the Pre-SiC fibre-tows surrounded and infiltrated by pre-pyrolyzed PyC interface ${ }^{3-6}$. A successful application of fabrication improvement was carried out ${ }^{8}$, and this new fabrication technique through controlling of the known defects is based on the understanding of both of that the erosive wear mechanisms and the crucial fabrication factors. Consequently, the robust microstructure was obtained in final product of $\mathrm{SiC} / \mathrm{SiC}$ composite.
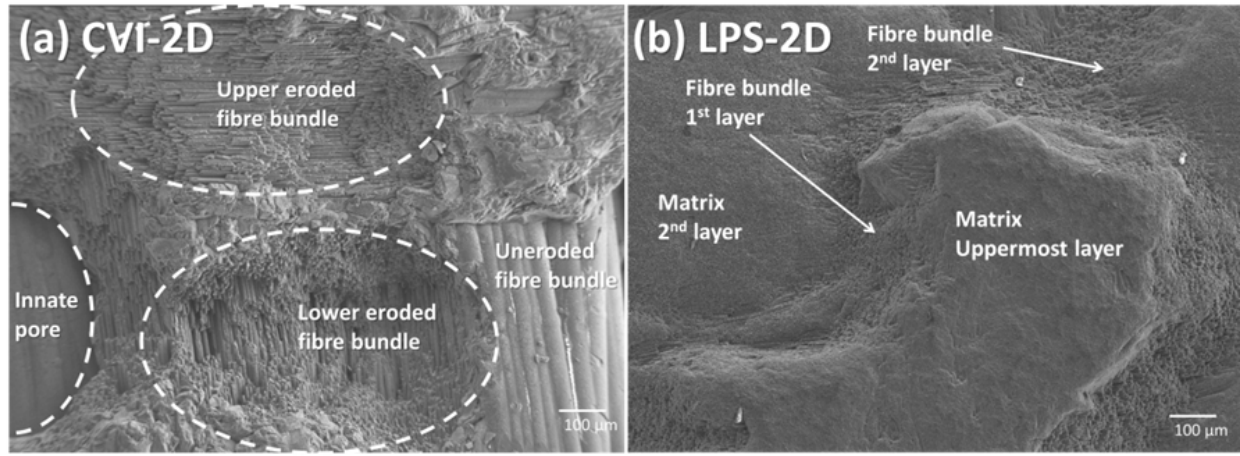

\section{(c) LPS-2D (cross-sectional view)}

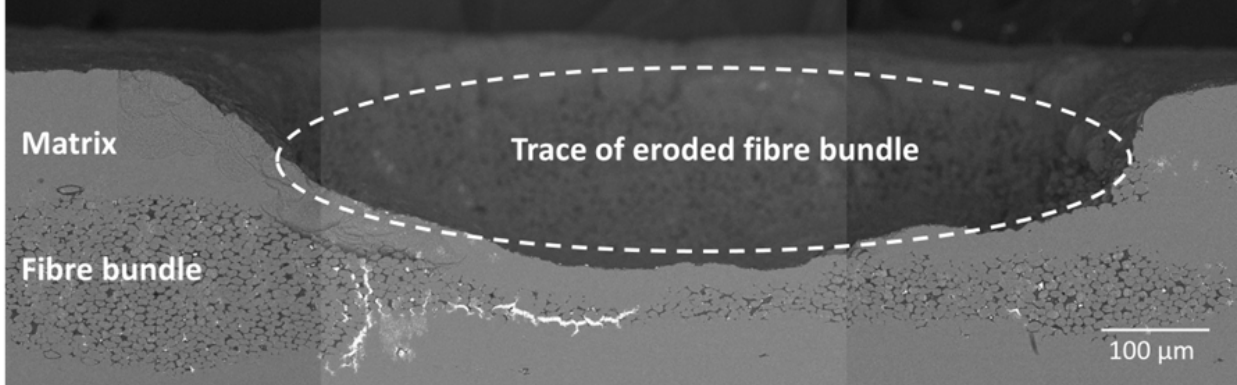

Fig. 2. SE micrographs showing the erosive wear behaviours on the superior strength of matrix and inferior strength of fibre bundle against erosion on $\mathrm{SiC} / \mathrm{SiC}$ composites fabricated by various route (a) CVI, (b) LPS, and (c) LPS with Pre-pyrolysis of phenolic resin interfaced fibre-reinforcement 
The depending issue of fibre deformation was rather serious ${ }^{5}$; however as shown in Fig. 3 our recent activity on fabrication improvement successfully settled the issue even at the same amount of pressure.

Besides, it was also confirmed that the crucial defects in prototype composites that significantly deteriorate the mechanical strength ${ }^{4-6}$ was porosity, in other words, erosive wear rate have linear correlation as a function of porosity ${ }^{4}$.
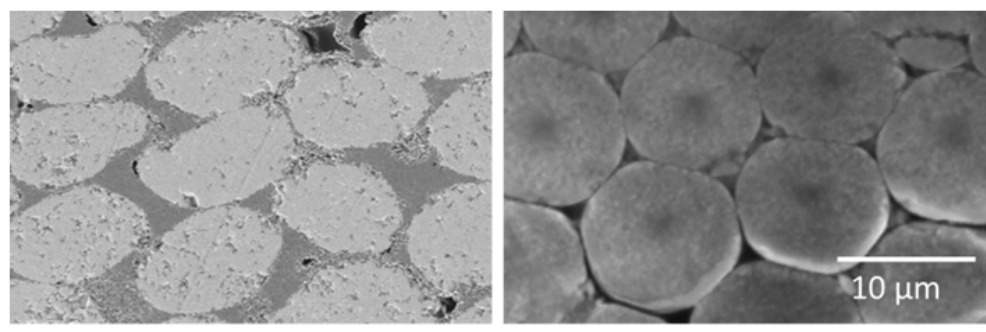

Fig. 3. Microstructure of $\mathrm{SiC} / \mathrm{SiC}$ composite by phenolic resin interfaced LPS route shows the fibre deformation ratio of (a) conventional method, and (b) improved method

\subsection{Particle Erosion Mechanism}

Erosive wear mechanisms on various $\mathrm{SiC} / \mathrm{SiC}$ composites based on the analysis of erosive wear behaviour are determined in elsewhere ${ }^{5,6}$. Despite the superiority of $\mathrm{SiC} / \mathrm{SiC}$ composites, due mainly to the graceful failure under loading ${ }^{3-7}$, the brittle fracture was still a dominant fracture mechanism. In fact, the role of interface between the matrix and the fibre-tow is to assist the crack readily propagates, but eagerly looking forward to be fractured only within the interface for the purpose of accomplishment on the desired fracture toughness. Crack propagation, generated by the solid particles, governs by the bonding strength of each constituent viz. fibre-tows, matrix, and interface ${ }^{6-8}$, that mostly propagates through the weakest link is generally known as a dominant erosive wear mechanism of composites under erosion ${ }^{5-7}$.

High bonding strength among the constituents is surely required to endure the progressive damages of SPE. No matter the amount of erosive wear, the erosive wear mechanisms for the CVI and the LPS composites are remarkably different.

Analysis of amply proved previous experiments shows, as illustrated as Fig. 4, the correlations of erosive wear resistance versus the porosity and erosive wear volume versus the strength of constituents are as inverse proportional and proportional, respectively. Matrix is strong enough that continuously endures the successive impingement of particles, and the interface bonding strength greatly affects to the erosive wear volume; for example the high bonding between the matrix and fibre bundles will result in gradual eroding of each fibre-tow as the dominant erosive wear behaviour. In the opposite, if the bonding strength between the matrix and fibre bundles is too weak to endure the impact of impingement then no matter how the strength of fibre-bundles, it will probably more chance to provoke the delamination of two constituents before the eroding of fibre-tows took placed. 
The strength of fibre is rather strengthlessly connected to the erosive wear resistance so that the wear volume of fire bundles are will rapidly increased with the increase of erosion impact. Nevertheless the strength of fibre insignificantly affects the erosive wear resistance due to the weak eroding nature. In case of fibre-tow, fracture damage and fragmentation conspicuously-easily occurs that it could hardly endeavour to resist the impact from the solid particles.
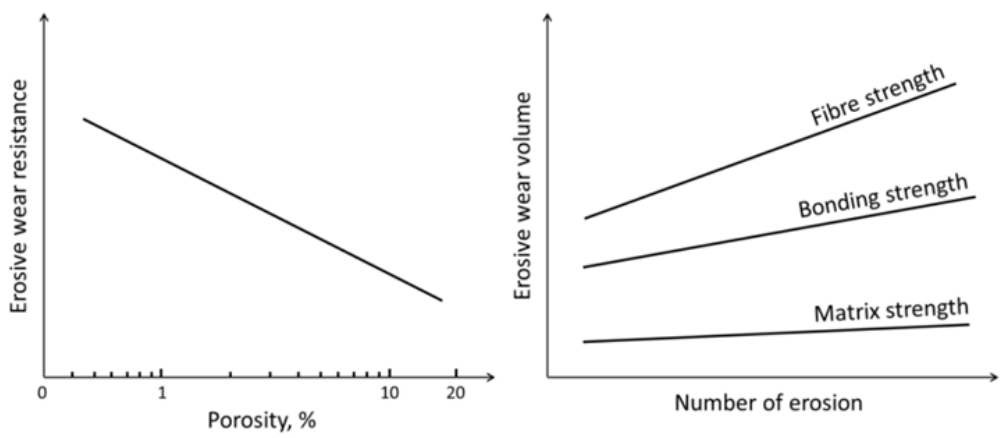

Fig. 4. Correlation of (a) erosive wear resistance versus the porosity, and (b) erosive wear volume versus the strength of each constituent of composite material viz. matrix, fibre, and interface

Most of all, the strength of matrix seems to govern the erosive wear resistance of $\mathrm{SiC} / \mathrm{SiC}$ composite under solid particle erosion. As depicted in Fig. 2, the eroding of uppermost layer of matrix starts, as a result the composite material endure several more number of erosion than the others when the strength of matrix is relatively stronger. Since the fracture of $1^{\text {st }}$ matrix layer occurs the eroding of fibre bundles initiated with relatively faster speed than that of the matrix eroding. Similarly, series of the eroding and the fracture of $2^{\text {nd }}$ and $3^{\text {rd }}$ matrix layer successively embarked on $\mathrm{SiC} / \mathrm{SiC}$ composites, this will lead to the fibre bundle eroding underneath. No matter how much the importance of erosive wear for aerospace industry, there was few works regarding $\mathrm{SiC} / \mathrm{SiC}$ composite under $\mathrm{SPE}^{10}$.

\section{Concluding Remarks}

The overall study from monolithic ceramics to ceramic composites underpinning that doubtlessly the necessity of composites is essential. However, the recent work on $\mathrm{SiC} / \mathrm{SiC}$ composites in the hot-section of aerospace propulsion system such as turbine blade, vane and rotor where it is superiorly beneficial has yielded a wide range of new results and new questions regarding the use of these materials. If such a material becomes a viable structural materials, its application offers several advantages in the areas of not only durability and reliability but also safety, maintenance and material squander over conventional materials, and would bring a superior reason of material science and engineering. These applications are promising due mainly to high temperature strength in excess of $1500{ }^{\circ} \mathrm{C}$, high ductility, graceful failure under loading, and high wear resistance, and high corrosion resistance where $\mathrm{SiC} / \mathrm{SiC}$ composite is certainly beneficial. 
However, the prime question of "how to design for the utmost performance" is still remained. Consequently, designing the guideline for $\mathrm{SiC} / \mathrm{SiC}$ composites for the pursuit of higher erosion performance might have to consider the followings.

Volume fraction of matrix on the top surface have to be greater than fibre bundles that it can take a role as the protecting layer, though be sure to consider the overall performance of impact damages since monolithic is significantly vulnerable to ballistic impact.

The strength of matrix is chiefly dependent on porosity, which is one of a form of many kinds of undesired impurities in $\mathrm{SiC} / \mathrm{SiC}$ composites.

Strengthen the bonding of each constituent is a crucial fabrication technique for high erosion performance; and the interface itself must cordially guide the propagation of crack to promise the fracture toughness, for that purpose multi-interface is one of the option.

The coating of PyC interface is prerequisite, however -in order to overcome issue of extremely high cost for wide industrial usages- it has two restrict requirements for erosion application that is being concise and cost effective.

\section{Acknowledgments}

The first author would like to acknowledge the supports of the Priority Research Center Program through the National Research Foundation of Korea (NRF) funded by the Ministry of Education, Science and Technology (2010-0028287).

\section{References}

1. M.-S. Suh, B. Kim and S.-S Kim "Tribological Evaluation of Structural Ceramics under Sliding Friction", International Journal of Modern Physics B 20(25-27), 4407-4412, 2006.

2. M.-S. Suh, Y.-H. Chae and S.-S Kim "Friction and Wear Behavior of Structural Ceramics Sliding against Zirconia”, Wear 264(9-10), 800-806, 2008.

3. M.-S. Suh, T. Hinoki, A. Kohyama "Erosion Wear Mechanism of $\mathrm{SiC}_{\mathrm{f}} / \mathrm{SiC}$ Composites by Solid Particles", World Tribology Congress 2009 Proc., Kyoto Japan, p. 909. 2009

4. M.-S. Suh, A. Kohyama "Effect of Porosity on Particle Erosion Wear Behavior of Lab. Scale $\mathrm{SiC}_{\mathrm{f}} / \mathrm{SiC}$ Composites”, Int. J. of Mod. Phys. B 24(15-16) 2934-2939, 2010

5. M.-S. Suh, et al. "Particle Erosion Wear Behaviour of New Conceptual SiC/SiC Composites", Ceramic Engineering and Science Proceedings 31(2), 275-284, 2010

6. M.-S. Suh, et al. "Threshold of Ring Crack Initiation on Ceramic Materials under Particle Impact", Ceramic Engineering and Science Proceedings 31(2), 285-294, 2010

7. M.-S. Suh, T. Hinoki, and A. Kohyama "Erosive Wear Mechanism of New $\mathrm{SiC} / \mathrm{SiC}$ Composites by Solid Particles", Tribology Letters - in press DOI:10.1007/s11249-010-9658-5

8. M.-S. Suh, K. Shimoda and T. Hinoki "Fabrication of $\mathrm{SiC}_{\mathrm{f}} / \mathrm{SiC}$ by means of in situ Crystallization of SiC Fibers", Journal of Nuclear Materials - in press DOI: 10.1016/j.jnucmat.2010.12.081

9. S.R. Choi "Foreign Object Damage Phenomenon by Steel Ball Projectiles in a $\mathrm{Sic} / \mathrm{SiC}$ Ceramic Matrix Composite at Ambient and Elevated Temperatures", J. Am. Ceram. Soc., 91(9) 2963-2968, 2008

10. B.-Q. Wang "Erosion Behaviour of SiC Fiber-SiC Matrix Composites" Wear 138, 125-136, 1990 